\title{
Modal Identification of Seismically Isolated Bridges with Piers Having Different Heights
}

\author{
Georgios Kampas, Nicos Makris
}

\begin{abstract}
This paper investigates the modal identification of seismically isolated bridges when the localized nonlinear behavior from the isolation bearing initiates at different times due to the uneven height of the bridge piers. More specifically, a three-span bridge supported on spherical sliding bearings is examined. Three different states of the same system with different natural periods emerge during an excitation; the linear system (LS), the partially isolated system (PIS) and the fully isolated system (FIS). Firstly, the paper identifies the time intervals that each state performs by using acceleration data. Subsequently, modal identification techniques such as the Prediction Error Method and a time-frequency wavelet analysis are applied on each interval. The LS' results are dependable compared to the PIS which is a mildly nonlinear system. The results corresponding to the FIS suggest that it is preferable to apply the modal identification techniques on each interval independently, rather than on the entire response signal.
\end{abstract}

Keywords: Seismic Isolation; Modal Identification; Dynamic Response; Bilinear Behavior; Time-Frequency Analysis; Bridge; Earthquake Engineering; Prediction Error Method; Structural Health Monitoring

\section{Introduction}

Seismic isolation is a widely accepted technology for protecting structures from strong earthquake shaking (Skinner et al., 1993; FHWA, 1995). Initially, bearings were used in bridges between the deck, the piers and the abutments for accommodating the thermal movements, while the experience gained through the years lead to its implementation as a most promising earthquake protection strategy (Kelly, 1997). The most commonly used isolation bearings are the lead rubber elastomeric and the spherical sliding bearings.

Fig. 1 shows the elevation of a recently constructed bridge in central Greece (Makris et al. 2010). The bridge is isolated with a pair of spherical sliding bearings (SSB) with radius of curvature, $R=2.2 \mathrm{~m}$, on each abutment and pier. The isolation period of the devices that corresponds to the aforementioned curvature in any horizontal direction is $T=2 \pi \sqrt{R / g}=2.2 s$. The SSBs have an initial deformation, $u_{y}=0.00025 \mathrm{~m}=0.25 \mathrm{~mm}$, as a function of the thickness of the material of the interface before the sliding initiates. The mean value of the friction coefficient of the isolation system is $\mu=0.045=4.5 \%$. The relation between the force, $F(t)$, and the displacement, $u(t)$, of a SSB with radius $R$ is described from 


$$
F(t)=\frac{N}{R} u(t)+\mu N \operatorname{sgn}[\dot{u}(t)]
$$

where $N$ is the vertical force applied on the bearing and $\mu$ the mean friction coefficient of the interface respectively. The force-displacement hysteretic loop is presented in Fig. 2.

Furthermore, the bridge of Fig.1 is a continuous, three-span, reinforced concrete, box girder bridge with $126 \mathrm{~m}$ long deck. The heights of the supporting piers $M_{1}$ and $M_{2}$ are respectively $25.97 \mathrm{~m}$ and $10.38 \mathrm{~m}$, following the morphology of the terrain. Fig. 2 (left) also displays the transverse restrains at the end abutment of the railway bridge for avoiding the misalignment of the rails at the deck-abutment joint during earthquake shaking. The bridge of Fig. 1 is fully isolated in the longitudinal direction, while it is restrained at the end-abutments in the transverse direction.

Railway bridges are important lifeline systems part of major transportation systems vital for the economy and society. In this paper we investigate and address some of the challenges that emerge from the interpretation of recorded acceleration data given that the sliding of the bearings of the bridge initiates at different times because of the uneven heights of the piers.

Modal identification is a subcategory of SHM and has been associated mostly with frequency domain methods. However, over the years, various powerful time domain methods have been developed and applied successfully. One of these methods that can be applied for the identification of modal periods is the Prediction Error Method (PEM). It initially emerged from the maximum likelihood framework of Aström and Bohlin (1965) and was advanced and became popular to system identification engineers as a MATLAB (2002) identification toolbox, which was developed following the theory by Ljung $(1987 ; 1994 ; 2002)$. In addition to PEM, another powerful tool that involves engineer's judgment is time-frequency analysis and more specifically, the extended wavelet transform (EWT) introduced by Vassiliou and Makris (2011) as an extension of the classical wavelet transform (Mallat 1999, Addison 2002 and references reported therein) for interrogating signals.

This paper builds upon the work of Kampas and Makris (2012); the natural period of a seismically isolated deck is better expressed with the second slope of the hysteretic loop, $T_{2}$, than with the geometric concept of the "effective period" which has no physical meaning (Kampas and Makris, 2012; Makris and Kampas, 2012; Kampas and Makris 2014). Analytical studies of the modal analysis of seismically isolated bridges when the deck is laterally restrained at the end abutments have been presented recently by Makris et al. (2010) and when the deck is laterally free at the end abutments by Kampas and Makris (2012).

\section{Statement of the problem}

Fig. 3 shows the mechanical idealization of the isolated bridge of Fig. 1 along the longitudinal and transverse directions. In the longitudinal direction, the deck is assumed rigid thus the bridge can be considered as a single degree of freedom system (SDOF). 
On the contrary, along the transverse direction the bridge is treated as a simply supported at the end abutments flexural beam on discrete stiffness elements (bearings).

Fig. 4 (left) shows the cross section of piers $M_{1}$ and $M_{2}$ and Fig. 4 (right) the momentcurvature diagram by implementing Mander model (Mander et al. 1988). Fig. 5 presents the pushover curves of the piers in both the longitudinal and transverse directions respectively. Fig. 5 (right) highlights the lateral force needed to initiate sliding in the $\mathrm{SSB}$ at each pier is $F_{L}=0.9 M N$. For pier $M_{1}$, the $F_{L}$ value corresponds to $0.6 \mathrm{~mm}$ displacement and for $M_{2}$ to $5.5 \mathrm{~mm}$ in the longitudinal direction. Consequently, when the deck experiences displacements in the range of $\left[\begin{array}{ll}0.0 & 0.6\end{array}\right) \mathrm{mm}$ the SSBs are not sliding, thus the bridge performs linearly in the longitudinal direction (linear system). In the range of $\left[\begin{array}{ll}0.6 & 5.5\end{array}\right) \mathrm{mm}$ the SSBs at pier $M_{2}$ become engaged contrarily to the SSBs at $M_{1}$. In this case, the bridge changes its dynamic characteristics and becomes merely isolated (partially isolated system). In the range of [5.5 $\max ] \mathrm{mm}$ both SSBs become engaged thus the bridge becomes fully isolated in the longitudinal direction. It is evident that the bridge of Fig.1 may respond dynamically during a single event by exhibiting three distinct periods depending on the amplitude of the response. The abovementioned problem can be further visualized in Fig. 6 where the deck imposes a common displacement to all piers and the tall piers deform accordingly in comparison to the shorter piers that need the additional deformation of the bearings to accommodate the deck's displacement. The manifestation of the different periods according to the level of shaking is a challenge to the modal identification of bridges having piers with uneven heights.

This challenge further increases when one considers the situation with a bridge having $n$ piers and $n$ bearings but with $k$ engaged bearings ( $k \leq n)$, under the assumption that the pier stiffnesses, $k_{i}^{\text {pier }}$, are inversely proportional to their numbering on the figure, $i$, as $k_{i}^{\text {pier }} \propto \frac{1}{i}$. Additionally, the SSB's natural period is considered to be the period associated with the second slope of the bilinear system, $T_{2}^{S S B}=2 \pi \sqrt{\frac{m}{k_{2}}}=3.0 \mathrm{~s}$ (Kampas and Makris 2012; Makris and Kampas 2012). Fig. 7 presents the modal periods of the distinct states emerging from the $k$ engaged bearings at $n$ piers. When $k=n$, the modal period of the total SDOF system becomes $T=T_{2}^{S S B}=3.0 \mathrm{~s}$.

It is evident from Fig. 7 that the differences between each state's modal period is not negligible, thus it is important to be able to identify the different time intervals in which each state of the system is responding during an event.

In the case of the bridge of Fig. $1, n=2$ so there could be three potential, emerging states; the linear system (LS) with $k=0$, the partially isolated system (PIS) with $k=1$ (the SSB of M2) and the fully isolated system (FIS) with $k=2$, respectively. 
Tables 1 and 2 present the modal periods of the abovementioned systems in the longitudinal and transverse direction, respectively.

\section{Proposed Methodology for Modal Identification}

As mentioned in the previous section, during a dynamic event, the deck's total response signal might be misleading for back-figuring the dynamic characteristics of the bridge, since it is composed from the sequential responses of the emerging states of the system. Thus, it is essential to develop methods to identify the distinct time intervals that correspond to each state on the deck output record.

It is assumed that the bridge has either linear variable differential transducers (LVDTs) or accelerometers above and below the isolation bearings at each pier.

A first way to identify the engagement interval of each SSB is to extract the information from its relative displacement signal deduced from the LVDTs' records (e.g. criterion: $\left.|u(t)|>u_{y}=0.00025 \mathrm{~m}\right)$.

However, the most usual device for structural health monitoring projects is the accelerometer. Another way to identify the different intervals is to extract the relative acceleration signal from the accelerometers above and below the isolators at each pier and use it to construct the equivalent internal variable of the Bouc Wen model (Wen $1975 ; 1976), z(t)$, as shown in eq. (2),

$$
\{Y\}=\left\{\begin{array}{c}
Y_{1} \\
Y_{2} \\
Y_{3}
\end{array}\right\}=\left\{\begin{array}{c}
u(t) \\
\dot{u}(t) \\
z(t)
\end{array}\right\} \Rightarrow\{\dot{Y}\}=\left\{\begin{array}{c}
\dot{Y}_{1} \\
\dot{Y}_{2} \\
\dot{Y}_{3}
\end{array}\right\}=\left\{\begin{array}{c}
\dot{u}(t) \\
\ddot{u}(t) \\
\dot{z}(t)
\end{array}\right\}=\left\{\begin{array}{c}
\frac{d u(t)}{d t} \\
\text { recorded data } \\
\frac{1}{u_{y}}\left[\gamma|\dot{u}(t)| z(t)|z(t)|^{m-1}+\beta \dot{u}(t)|z(t)|^{m}-\dot{u}(t)\right]
\end{array}\right.
$$

where $Y$ is the state vector, $u(t), \dot{u}(t)$ and $\ddot{u}(t)$ are the displacement, the velocity and the acceleration of the SSB respectively, $z(t)$ is a variable that takes values from $\left[\begin{array}{ll}-1 & 1\end{array}\right], u_{y}$ is the initial deformation $=0.00025 \mathrm{~m}$ and $\beta, \gamma$ are internal parameters of the Bouc-Wen model that control the shape of the hysteretic loop. More specifically, if the SSB is sliding the $z(t)=-1$ or 1 , else $z(t) \in\left(\begin{array}{ll}-1 & 1\end{array}\right)$. Accordingly, the engagement interval of each SSB is defined from the first value of -1 or 1 to the last value- 1 or 1 in the $z(t)$ signal as shown in Fig. 8.

If $t_{1}{ }^{M 1}$ and $t_{2}{ }^{M 1}$ is the time of the initiation and the ending of the sliding of the SSB at pier $M_{1}$ and $t_{1}{ }^{M 2}$ and $t_{2}{ }^{M 2}$ at pier $M_{2}$ respectively, by assuming that $t_{1}{ }^{M 2}<t_{1}{ }^{M 1}$ , the distinct time intervals will form as:

- $t \in\left[\begin{array}{ll}0 & t_{1}^{M 2}\end{array}\right]$ is when the LS is performing, as there is no sliding occurance.

- $t \in\left[t_{1}{ }^{M 2} t_{1}{ }^{M 1}\right]$ is when the PIS is performing, since only the SSB at pier $M_{2}$ is engaged.

- $t \in\left[t_{1}{ }^{M 1} t_{2}{ }^{M 1}\right], t_{2}{ }^{M 1}<t_{2}{ }^{M 2}$ is when the FIS is performing.

- $t \in\left[t_{2}{ }^{M 1} t_{2}{ }^{M 2}\right]$ is when PIS is performing, since the SSB at pier $M_{1}$ is "locked". 
- $t \in\left[t_{2}{ }^{M 2}\right.$ end $)$ is when the LS is performing, as the SSB at pier $M_{2}$ is "locked" also.

The PIS and the FIS are mildly nonlinear systems, thus trying to identify a modal period from their corresponding time interval would be a challenge. Kampas and Makris (2012) proposed the index in eq. (3) for deciding whether the results are dependable or not.

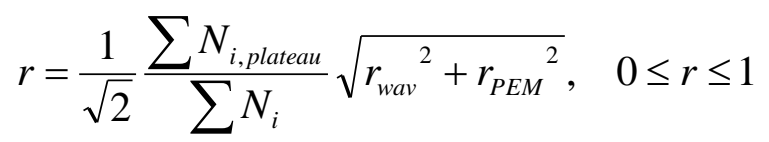

where $\frac{\sum N_{i, \text { plateau }}}{\sum N_{i}}$ is the ratio of the points on the plateaus in the engagement interval of $z(t)$ divided by the total number of points in the engagement interval (defined as engagement index), $r_{w a v}$ is the matching index that possess the value 1 if the best matching wavelet (output of the wavelet method) is perfectly correlated with the acceleration record and the value 0 if there is no correlation between them, and $r_{P E M}$ is the matching index that correlates the output signal of prediction error method (PEM) with the actual acceleration record as shown in eq.(4).

$$
r_{w a v}=\frac{\int_{0}^{T}|\psi(t) \ddot{u}(t)| d t}{\int_{0}^{T} \ddot{u}^{2}(t) d t} \text { and } r_{P E M}=\frac{\int_{0}^{T}|a(t) \ddot{u}(t)| d t}{\int_{0}^{T} \ddot{u}^{2}(t) d t}
$$

More details about the application of the PEM and the wavelet analysis as modal identification methods can be found in Kampas and Makris $(2011$; 2012). The estimation of the index $r$ (which becomes $r_{1}, r_{2}, r_{3}, \ldots, r_{n}$ for $n$ piers), would suggest whether the modal periods identified are reliable $\left(r=\min \left(r_{i}\right)>0.5\right)$ or not $\left.r=\min \left(r_{i}\right)<0.5\right)$.

The methods implemented in this study to identify the modal characteristics range from time domain methods such as the Prediction Error Method (PEM) to time-frequency analysis and wavelets.

\section{The Prediction Error Method (PEM)}

The prediction error methods belong to a broad family of parameter estimation methods that can be applied to arbitrary model parameterizations (Ljung 2002). Given an output $y(t)$ due to an input $u(t)$ at time $t$, the target is to identify the parameters of the selected model. The recordings are discrete in time and let $Z^{N}=\{u(1), y(1), u(2), y(2), \ldots u(N), y(N)\}$ be all the past data recorded up to time $t=N$. The basic idea that lies behind these methods is that the model can be described as a predictor of the next output point as a function of the past history,

$$
\hat{y}_{m}(t \mid t-1)=f\left(Z^{t-1}\right)
$$


where $\hat{y}_{m}(t \mid t-1)$ accounts for the predictor, and $f\left(Z^{t-1}\right)$ for the chosen, arbitrary function of past data. The next conceptual step is to parameterize the predictor using a parameter vector, $\bar{\theta}$,

$$
\hat{y}(t \mid \boldsymbol{\theta})=f\left(Z^{t-1}, \boldsymbol{\theta}\right)
$$

The method's final outcome is an estimate of the parameter vector $\theta, \theta_{N}$, according to the minimization of an appropriate norm which represents the distance, $V_{N}(\theta)$, between the predicted $\{y(1 \mid \boldsymbol{\theta}), \ldots, y(N \mid \boldsymbol{\theta})\}$ and the recorded output $\{y(1), \ldots, y(N)\}$ :

$$
V_{N}(\boldsymbol{\theta})=\sum_{t=1}^{N} l(y(t)-\hat{y}(t \mid \boldsymbol{\theta}))=\sum_{t=1}^{N} l\left(y(t)-f\left(Z^{t-1}, \boldsymbol{\theta}\right)\right)
$$

where $l=\|y(t)-\hat{y}(t \mid \boldsymbol{\theta})\|^{2}$ is a suitable distance measure. The parameter vector $\hat{\theta}_{N}$ is calculated by minimizing the above norm,

$$
\hat{\theta}_{N}=\arg \min _{\theta} V_{N}(\boldsymbol{\theta})
$$

\section{Time-Frequency Wavelet Analysis}

Over the last two decades, wavelet transform analysis has emerged as a unique new time-frequency decomposition tool for signal processing and data analysis. There is a wide literature available regarding its mathematical foundation and its applications (Mallat 1999, Addison 2002 and references reported therein). Wavelets are simple wavelike functions localized on the time axis. For instance, the second derivative of the Gaussian distribution, $e^{-t^{2} / 2}$, known in the seismology literature as the symmetric Ricker Wavelet (Ricker 1943, 1944; and widely referred as the "Mexican Hat" wavelet, Addison 2002),

$$
\psi(t)=\left(1-t^{2}\right) e^{-t^{2} / 2}
$$

is widely used in wavelet analysis. In order for a wavelike function to be classified as a wavelet, the wavelike function must have (Addison 2002) : (a) finite energy

$$
E=\int_{-\infty}^{\infty}|\psi(t)|^{2} d t<\infty
$$

and (b) a zero mean. In this proposal we are merely interested to achieve the best local matching of any given acceleration record with a wavelet that will offer the best estimates of the period ( $T_{p}=$ time scale) and amplitude $\left(a_{p}\right.$, since $a_{p} T_{p}^{2}=$ length scale $)$ of the prevailing energetic pulse. Accordingly, we perform a series of inner products (convolutions) of the response acceleration signal, $\ddot{u}(t)$, with the wavelet $\psi(t)$ by manipulating the wavelet through a process of translation (i.e. movement along the time axis) and a process of dilation-contraction (i.e. spreading out or squeezing of the wavelet)

$$
C(s, \xi)=w(s) \int_{-\infty}^{+\infty} \ddot{u}(t) \psi\left(\frac{t-\xi}{s}\right) d t
$$

The values of $s=S$ and $\xi=\Xi$, for which the coefficient, $C(s, \xi)=C(S, \Xi)$ becomes maximum offer the scale and location of the wavelet $w(s) \psi\left(\frac{t-\xi}{s}\right)$ that locally matches best the acceleration record, $\ddot{u}(t)$. Equation (11) is the definition of the wavelet transform. The quantity $w(s)$ outside the integral in equation (11) is a weighting 
function. Typically $w(s)$ is set equal to $1 / \sqrt{s}$ in order to ensure that all wavelets $\psi_{s, \xi}(t)=w(s) \psi\left(\frac{t-\xi}{s}\right)$ at every scale $s$ have the same energy, and according to equation (10)

$$
\int_{-\infty}^{\infty}\left|\psi_{s, \xi}(t)\right|^{2} d t=\int_{-\infty}^{\infty}\left|\frac{1}{\sqrt{s}} \psi\left(\frac{t-\xi}{s}\right)\right|^{2} d t=\left\|\psi_{s, \xi}(t)\right\|_{2}=\text { constant }, \quad \forall s
$$

The same energy requirement among all the daughter wavelets $\psi_{s, \xi}(t)$ is the default setting in the MATLAB wavelet toolbox and what has been used by Baker (2007); however, the same energy requirement is, by all means, not a restriction. Clearly there are applications where it is more appropriate that all daughter wavelets $\psi_{s, \xi}(t)$ at every scale $s$ enclose the same area $(w(s)=1 / s)$ or have the same maximum value $(w(s)=1$ ).

For illustration purposes, Fig. 9 presents the acceleration response of a 2 dof oscillator when subjected to the 95 Erzincan record. The heavy dashed line presents the wavelet $\lambda(S, \Xi) w(S) \psi\left(\frac{t-\Xi}{S}\right)$ in which $\Xi$ and $S$ are the values of $\xi$ and $s$ that give the maximum coefficient $C(S, \Xi)$ from equation (11) in which $w(s)=1 / \sqrt{s}$. The multiplication quantity

$$
\lambda(S, \Xi)=\frac{C(S, \Xi)}{w^{2}(s) \cdot S \cdot E}
$$

where $E$ is the energy of the mother wavelet, is needed in order for the best matching wavelet, $\psi_{s, \Xi}(t)=w(s) \psi\left(\frac{t-\Xi}{S}\right)$, to assume locally the amplitude of the acceleration record. In the classical wavelet transform described above only dilation-contraction along with translation of the wavelet are allowed. There are signals though, that need even more mathematical flexibility from the wavelet used for obtaining more reliable results. Vassiliou and Makris (2011) developed a wavelet based on Gabor (1946)

and Mavroeidis and Papageorgiou (2003) that except translation, $\xi$, and dilationcontraction, $s$, allows also a modulation at the phase, $\varphi$, and the number of half-cycles, $\gamma$ as shown in equations (14) and (15),

$$
\begin{gathered}
\psi\left(\frac{t-\xi}{s}, \varphi, \gamma\right)=\left(\sin \left(\frac{2 \pi}{s \gamma}(t-\xi)\right) \cos \left(\frac{2 \pi}{s}(t-\xi)+\varphi\right)+\gamma \sin \left(\frac{2 \pi}{s}(t-\xi)+\varphi\right)\right)\left(1+\cos \left(\frac{2 \pi}{s \gamma}(t-\xi)\right)\right) \\
C(s, \xi, \varphi, \gamma)=w(s, \varphi, \gamma) \int_{-\infty}^{+\infty} \ddot{u}(t) \psi\left(\frac{t-\xi}{s}, \varphi, \gamma\right) d t
\end{gathered}
$$

where, $C(s, \xi, \varphi, \gamma)$ is the wavelet transform coefficients, $w(s, \varphi, \gamma)$ is a weighting function, $\ddot{u}(t)$ is the recorded acceleration, $\psi\left(\frac{t-\xi}{s}, \varphi, \gamma\right)$ is the wavelet of equation (14).

A proposed methodology for modal identification of isolated bridges from acceleration records is, 
- Estimate the number of the potential, emerging states of the bridge, $1+\sum_{i=1}^{n}\left(\begin{array}{l}n \\ i\end{array}\right)=1+\sum_{i=1}^{n} \frac{n !}{i !(n-i) !}$, which becomes $n+1$ for practical reasons, where $n$ is the number of piers with uneven height.

- Identify the different time intervals on the output signal, based on the engagement intervals of each SSB, and correlate them with the corresponding states. Consider $t_{j}^{i n}=\left[t_{1}^{i n} t_{2}^{i n} \ldots t_{n}^{i n}\right] \quad$ and $t_{j}^{\text {end }}=\left[t_{1}^{\text {end }} t_{2}^{\text {end }} \ldots t_{n}^{\text {end }}\right]$ the times of the initiation and the ending of the sliding of the SSBs at the $\mathrm{j}^{\text {th }}$ pier. Then, sort the values with ascending order, $t_{m}=\left[\min \left(t_{j}^{i n}\right) \ldots \max \left(t_{j}^{\text {end }}\right)\right], m=1, \ldots, 2 j$. The pairs of the successive elements of the vector $t_{m}$ form the different, successive time intervals.

- Apply the modal identification techniques on the individual time intervals.

- Estimate the indices $r_{1}, r_{2}, r_{3}, \ldots, r_{n}$ for each time interval to determine whether the results are dependable $\left(r=\min \left(r_{i}\right)>0.5\right.$ for individual interval).

\section{Case Study}

The bridge of Fig. 1 has been subjected to the six strong ground motions presented in Table 3. The bridge during the extreme loading performs according the mechanical idealization of Fig. 3. The analysis has been conducted with the commercially available software MATLAB (2002) and SAP (Computers and Structures 2006). The SSBs have been modeled according to the Bouc Wen model (Wen 1975; 1976). The results concerning the transverse direction confirm the results corresponding to the longitudinal direction and due to space limitation are not presented in this paper.

Furthermore, in the longitudinal direction the bridge behaves like a SDOF system. Fig. 10 presents the response of the bridge during the El Centro Array \#5 record.

Initially, the PEM and the wavelet method were applied on the total acceleration response of the deck. The results are shown in Fig. 11.

In this case, the number of piers is $n=2$, thus the number of emerging states of the system is three; the linear system (LS), the partially isolated system (PIS) and the fully isolated system (FIS). The next step is the identification of the different time intervals of the emerging states by using the internal variables $z_{B 1}(t)$ and $z_{B 2}(t)$ that correspond to the SSBs at the piers $M_{1}$ and $M_{2}$ respectively, as presented in Fig. 12.

From Fig. 12 it is evident that interval 1 corresponds to the PIS since the SSB at $M_{2}$ is sliding while the SSB at M1 is still "locked". Interval 2 corresponds to FIS since the SSBs at both piers are engaged, interval 3 to PIS and interval 4 to LS since there is no sliding occurrence.

Fig. 13 presents the response of the emerging states at the different time intervals in the case of the El Centro Array \#5 record. Fig. 14-17 present the modal periods identified at each individual interval respectively. Information about the LS can be deduced from 
interval 4 since no SSB is sliding. Interval 1 and 3 provide information about the PIS, as only the SSB at $M_{2}$ is engaged, and interval 2 provides information about the FIS.

Table 4 shows, that $r<0.5$ in most cases, thus the results are not dependable. However, it is promising that the modal periods presented in Fig. 15 are closer to actual values than the periods presented in Fig.11. Fig.18, 19 highlight this finding, as they compare the error of the identified modal periods from the total response signal of the deck to the error of the identified modal periods from time interval 2. Moreover, there are not big differences observed in the error of the wavelet method's results (Fig. 19) mostly because the method is acting "locally" in time thus is not affected from the presence of the rest of the record.

Interval 1 results exhibit $r<0.5$ since in most cases the quantity of data was not sufficient to deduce a dependable estimate of the modal period of PIS. Interval 3 results exhibit also $r<0.5$, although there was the appropriate quantity of data, as the engagement index's values were low $\left(\frac{\sum N_{i, p l a t a u}}{\sum N_{i}}\right)$. That is, the $z_{B 2}$ of the SSB at pier $M_{2}$ is unlikely to display a lot of points on the plateaus $\left(\sum N_{i, p l a t e a u}\right)$ and at the same time the SSB at pier $M_{1}$ to remain "locked".

The results from interval 4 (LS) are dependable.

\section{Conclusions}

This paper investigates the modal identification of seismically isolated bridges supported on piers with different heights. The uneven heights of the piers is responsible that in several occasions only a fraction of the isolation bearings engage in sliding motion (those atop the short, stiffer piers), given that the taller piers deflect more than the shorter piers. This situation results in the emerging of ephemeral states of the system with different modal periods that respond sequentially during the excitation.

One of the challenges that this paper addresses is the identification of the time intervals when each of the corresponding states of the system performs by constructing and using an internal Bouc-Wen variable, $z(t)$, from the accelerometers' data.

The paper investigates a 3-span bridge supported on spherical sliding bearings (SSB). When subjected to six historic, strong ground motions. In the longitudinal direction the bridge behaves like a SDOF system assuming that the deck remains rigid. In the transverse direction the deck's rigidity dominates the behavior, thus the bridge behaves like flexural beam on discrete stiffness elements.

The modal identification methods used in this paper are (a) the prediction error method (PEM) -that is a time domain method, and (b) a time-frequency analysis method that uses wavelet analysis. 
Three emerging states of the bridge are identified in the response in both horizontal directions; the linear system (LS) when no sliding of the SSBs occurs, the partially isolated system (PIS) when only the SSB at the short pier $M_{2}$ is engaged, and the fully isolated system (FIS) when the SSBs at both piers are engaged. The best matching index $r$, proposed by Kampas and Makris (2012), was used to validate the dependability of the results after the application of the modal identification techniques.

The results concerning the LS are dependable. On the contrary, the identified modal periods corresponding to the PIS were not reliably identified since there was neither the proper quantity (more than one cycle of vibration) nor the quality (low engagement index of each SSB) of the data in the respective time intervals.

Finally, the paper concludes that the error between the identified and the actual modal period is smaller if the period is identified from time interval 2 than from the total response signal of the bridge.

\section{REFERENCES}

Addison P. S. (2002), The illustrated wavelet transform handbook, Institute of Physics Handbook.

Aström, K. J., and Bohlin T. (1965), 'Numerical identification of linear dynamic systems from normal operating records', IFAC Symposium on Self-Adaptive Systems, Teddington, England.

Baker, W.J., (2007). 'Quantitative classification of near fault ground motions using wavelet analysis', Bull. Seism. Soc. Am., Vol. 97, pp. 1486-1501.

Computers and Structures, (2006), SAP 2000 Documentation, University of California, Berkeley.

FHWA, (1995), 'Seismic Retrofitting manual for Highway Bridges', U.S. Department of Transportation: U.S.A.

Gabor, D. (1946), 'Theory of communication. I. The analysis of information', IEEE Vol. 93, pp. 429-441.

Kampas, G. and N. Makris, (2010), The Eigenvalues of Seismic Isolated Bridges, Report No SEE 2010-01, Department of Civil Engineering, University of Patras, Greece.

Kampas, G. and Makris, N., (2012), 'Time and Frequency Domain Identification of Seismic Isolated Structures: Advantages and Limitations', Earthquakes and Structures, Vol. 3, pp. 249-267.

Kampas, G. and N. Makris, (2012), 'Transverse versus Longitudinal Eigenperiods of Multispan Seismically Isolated Bridges', Journal of Structural Engineering, ASCE, Vol. 138, pp. 193.

Kampas, G. and Makris, N., (2013), 'Modal Identification of Freeway Overcrossings with Soil-Structure Interaction: A case study', Structural Control and Health Monitoring, Vol. 20(3), pp. 304-319.

Kampas G. and N. Makris, (2014), 'Revisiting the "Effective" Period of Bilinear Isolation Systems Using Modal Identification Techniques', 6th WCSCM, World Conference on Structural Control and Health Monitoring, Barcelona, Spain. 
Kelly, J., M. (1997), Earthquake-Resistant Design with Rubber, Springer: London, U.K.

Ljung L. (1987), System Identification-Theory for the User', Prentice-Hall, New Jersey.

Ljung L. (1994), 'State of the Art in Linear System Identification: Time and Frequency Domain Methods', Proceedings of '04 American Control Conference, Vol. 1, pp. 650-660.

Ljung L. (2002), 'Prediction Error Estimation Methods', Circuits Systems Signal Processing, Vol. 21, pp. 11-21.

Makris N., G. Kampas and D. Angelopoulou, , (2010). 'Modal Analysis of Isolated Bridges with Transverse Restraints at the End-Abutments', in ACES Workshop: Advances in Performance-Based Earthquake Engineering, Corfu, Greece, pp. 331-339.

Makris, N., Kampas, G., and Angelopoulou, D., (2010), 'The eigenvalues of isolated bridges with transverse restraints at the end abutments', Earthquake Engineering and Structural Dynamics, Vol. 39, pp.869-886.

Makris N., and Kampas G., (2012). "Estimating the "Effective period" of Bilinear Systems with Linearization Methods, Wavelet and Time-Domain Analysis', Journal of Soil Dynamics and Earthquake Engineering, Vol. 45, pp. 80-88.

N. Makris and G. Kampas, (2012), The Engineering Merit of the "Effective Period" of Bilinear Systems, Report No EEAM 2012-01, Department of Civil Engineering, University of Patras, Greece.

Makris, N. and Kampas, G., (2013) 'The Engineering Merit of the "Effective Period" of Bilinear Isolation Systems', Earthquakes and Structures, Vol. 4(4), pp. 397428.

Mallat S. G. (1999), A wavelet tour of signal processing, Academic Press.

Mander J.B., Priestley M.J.N., and Park, P. (1988), 'Theoretical Stress-Strain Model for Confined Concrete', Journal of Structural Engineering, Vol. 114(8), pp. 1804-1826.

Mander J.B., Priestley M.J.N., and Park, P. (1988), 'Observed Stress-Strain Behavior of Confined Concrete', Journal of Structural Engineering, Vol. 114(8), pp. 1827-1849.

MATLAB, (2002), High-performance Language Software for Technical Computation, The MathWorks, Inc: Natick, MA.

Mavroeidis, G. P., A. S. Papageorgiou (2003), 'A mathematical representation of nearfault ground motions', Bull. Seism. Soc. Am., Vol. 93, pp. 1099-1131.

Ricker, N. (1943), 'Further developments in the wavelet theory of seismogram structure', Bull. Seism. Soc. Am., Vol. 33, pp.197-228. 314-323.

Ricker, N. (1944), 'Wavelet functions and their polynomials', Geophysics, Vol. 9, pp.

Skinner, R.I., Robinson, W.,H., McVerry, G., H. (1993), An Introduction to Seismic Isolation, Wiley, New York.

Vassiliou, M.F. and Makris, N. (2011), 'Estimating time scales and length scales in pulselike earthquake acceleration records with wavelet analysis', B. Seismol. Soc. Am., Vol.101(2), pp. 96-618.

Wen Y., K. (1975), 'Approximate method for nonlinear random vibration', Journal of Engineering Mechanics, Vol. 101(4), pp.389-401.

Wen Y., K. (1976), 'Method for random vibration of hysteretic systems', Journal of Engineering Mechanics, Vol. 102(2), pp.249-263. 


\section{TABLES}

Table 1. The modal periods of the different states of the bridge of Fig. 1 in the longitudinal direction.

\begin{tabular}{|l|c|}
\hline \multicolumn{1}{|c|}{ System in longitudinal direction } & $T_{L}(s)$ \\
\hline Linear System (LS) & 0.36 \\
\hline Partially Isolated System (PIS) & 0.95 \\
\hline Fully Isolated System (FIS) & 3.00 \\
\hline
\end{tabular}

Table 2. The modal periods of the different states of the bridge of Fig.1 in the transverse direction.

\begin{tabular}{|l|c|}
\hline \multicolumn{1}{|c|}{ System in transverse direction } & $T_{T}(s)$ \\
\hline Linear System (LS) & 0.67 \\
\hline Partially Isolated System (PIS) & 1.05 \\
\hline Fully Isolated System (FIS) & 1.09 \\
\hline
\end{tabular}

Table 3. Six historic, strong ground motions used as excitations in the nonlinear time history analyses of the bridge of Fig.1.

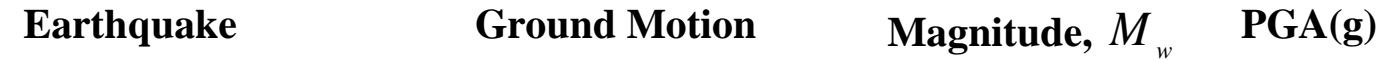

\begin{tabular}{cccc}
\hline 1979 Coyote Lake, CA & Gilroy Array \#6 230 & 5.7 & 0.43 \\
1979 Imperial Valley, CA & El Centro Array \#5 140 & 6.5 & 0.52 \\
1986 El Salvador & Geot. Inv. Center 180 & 5.5 & 0.48 \\
1992 Erzincan, Turkey & 95 Erzincan & 6.9 & 0.52 \\
1992 Cape Mendocino, CA & Cape Mendocino/000 & 7.2 & 1.49 \\
1995 Aigion, Greece & OTE Building & 6.2 & 0.54
\end{tabular}

Table 4. The matching indices $r_{P E M}$ and $r_{w a v}$, the engagement indices for $z_{B 1}$ and $z_{B 2}$ and the index $r$ for each time interval for all excitations.

\begin{tabular}{c|ccccc} 
Interval 1 & $r_{P E M}$ & $r_{\text {wav }}$ & eng. index $z_{B 1}$ & eng. index $z_{B 2}$ & $r$ \\
\hline El Centro Array \#5 & 0.62 & 0.35 & - & 0.21 & $\mathbf{0 . 1 1}$
\end{tabular}




\begin{tabular}{l|ccccc} 
95 Erzincan & 0.70 & 0.54 & - & 0.38 & $\mathbf{0 . 2 4}$ \\
OTE Building & -0.13 & 0.34 & - & 0.44 & $\mathbf{0 . 1 1}$ \\
Gilroy Array \#6 & 0.07 & 0.26 & - & 0.204 & $\mathbf{0 . 0 4}$ \\
Cape Mendocino/000 & -0.57 & 0.02 & - & 0.61 & $\mathbf{0 . 2 5}$ \\
Geot. Inv. Center 180 & -0.12 & 0.16 & - & 0.59 & $\mathbf{0 . 0 8}$ \\
\hline \multicolumn{1}{c}{ Interval 2 } & & & & & \\
\hline El Centro Array \#5 & 0.34 & 0.49 & 0.45 & 0.58 & $\mathbf{0 . 1 9}$ \\
95 Erzincan & -0.10 & 0.86 & 0.84 & 0.90 & $\mathbf{0 . 5 2}$ \\
OTE Building & 0.04 & 0.39 & 0.38 & 0.72 & $\mathbf{0 . 1 1}$ \\
Gilroy Array \#6 & 0.16 & 0.45 & 0.51 & 0.79 & $\mathbf{0 . 1 7}$ \\
Cape Mendocino/000 & 0.01 & 0.68 & 0.65 & 0.86 & $\mathbf{0 . 3 1}$ \\
Geot. Inv. Center 180 & 0.08 & 0.64 & 0.34 & 0.55 & $\mathbf{0 . 1 6}$ \\
\hline \multicolumn{1}{c}{ Interval 3 } & & & & & \\
\hline El Centro Array \#5 & 0.64 & 0.10 & - & 0.05 & $\mathbf{0 . 0 2}$ \\
95 Erzincan & 0.02 & 0.21 & - & 0.38 & $\mathbf{0 . 0 6}$ \\
OTE Building & 0.00 & 0.09 & - & 0.12 & $\mathbf{0 . 0 1}$ \\
Gilroy Array \#6 & 0.08 & 0.11 & - & 0.20 & $\mathbf{0 . 0 2}$ \\
Cape Mendocino/000 & 0.21 & 0.46 & - & 0.55 & $\mathbf{0 . 2 0}$ \\
Geot. Inv. Center 180 & 0.03 & 0.13 & - & 0.11 & $\mathbf{0 . 0 1}$ \\
\hline
\end{tabular}

\section{FIGURES}

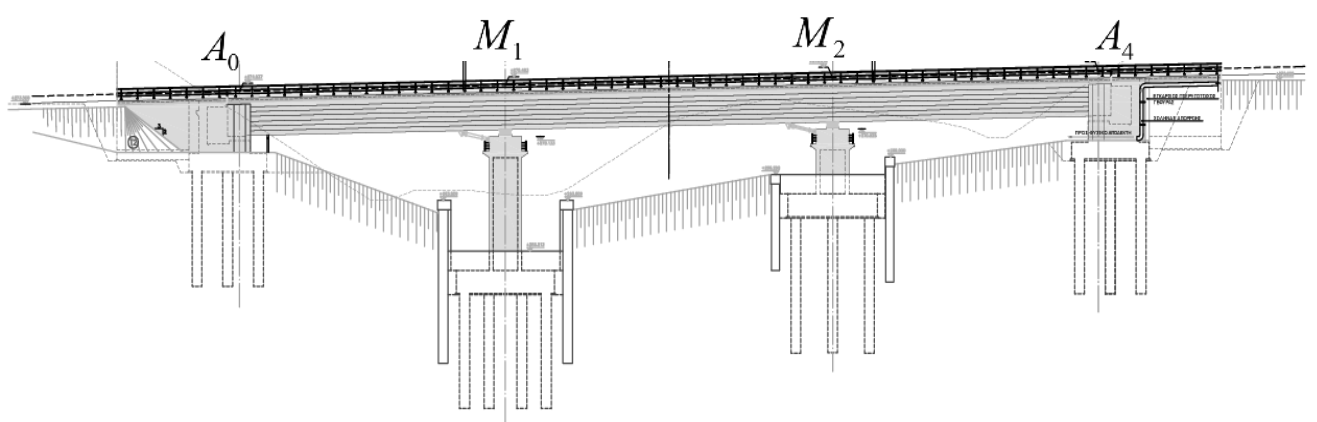

Figure 1. Elevation of a recently constructed seismically isolated bridge in central Greece. 


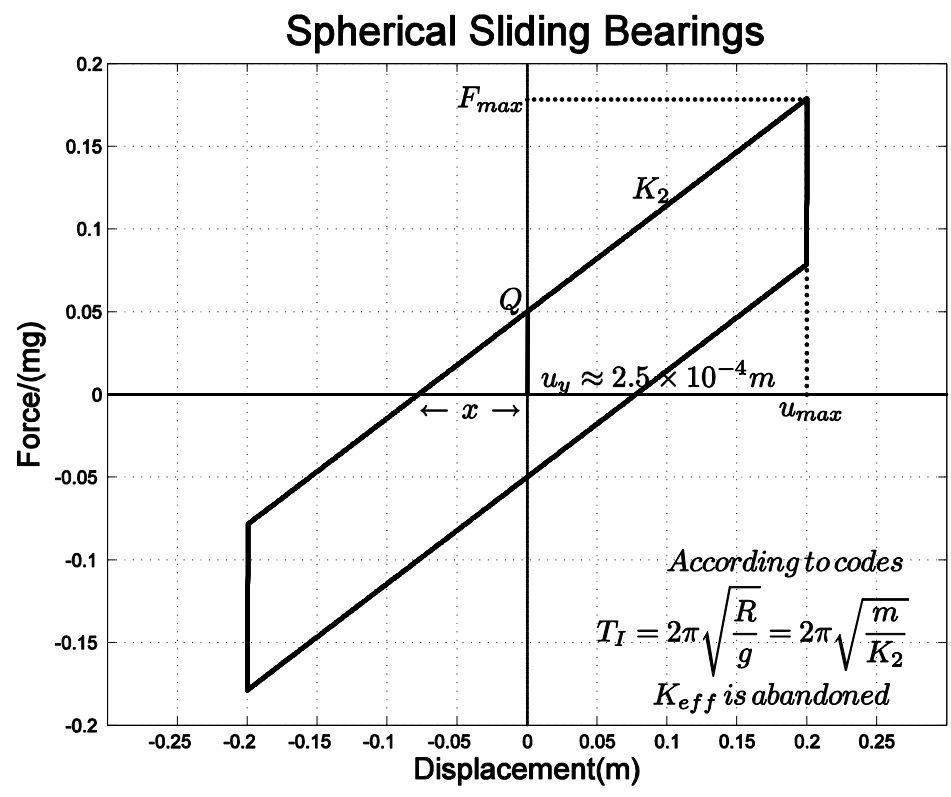

Figure 2. Force-displacement hysteretic loop of the spherical sliding bearing (SSB).

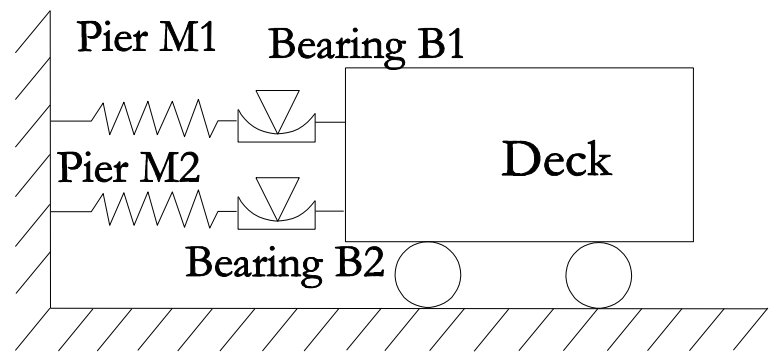

Abutment A0

Abutr

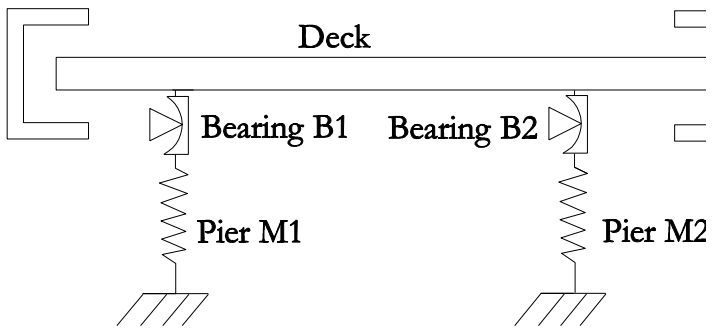

Figure 3. The mechanical idealization of the isolated bridge of Fig.1 in the longitudinal (left) and transverse direction (right).
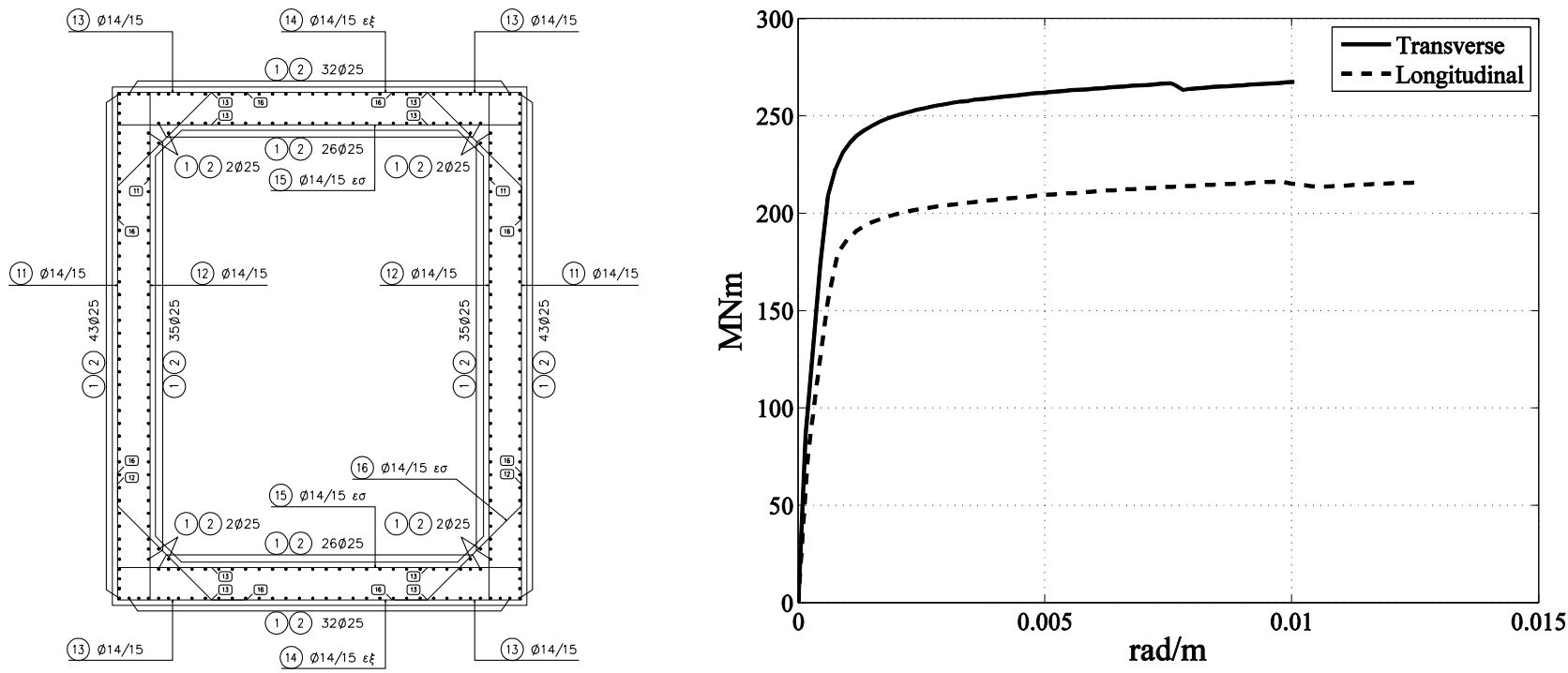
Figure 4. The cross section of the pier $M_{1}$ and $M_{2}$ (left); Moment-curvature of the piers $M_{1}$ and $M_{2}$ (right).
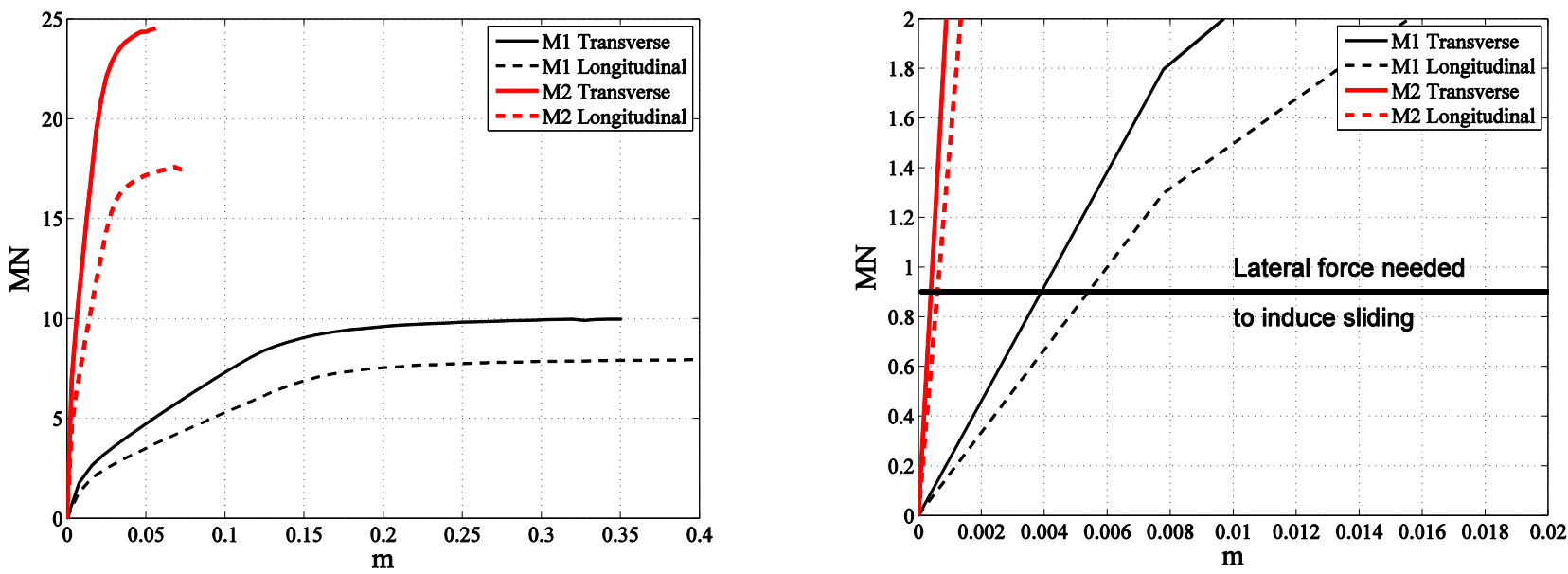

Figure 5. Pushover curves of the piers $M_{1}$ and $M_{2}$ (left); focus on the pushover curves (right).

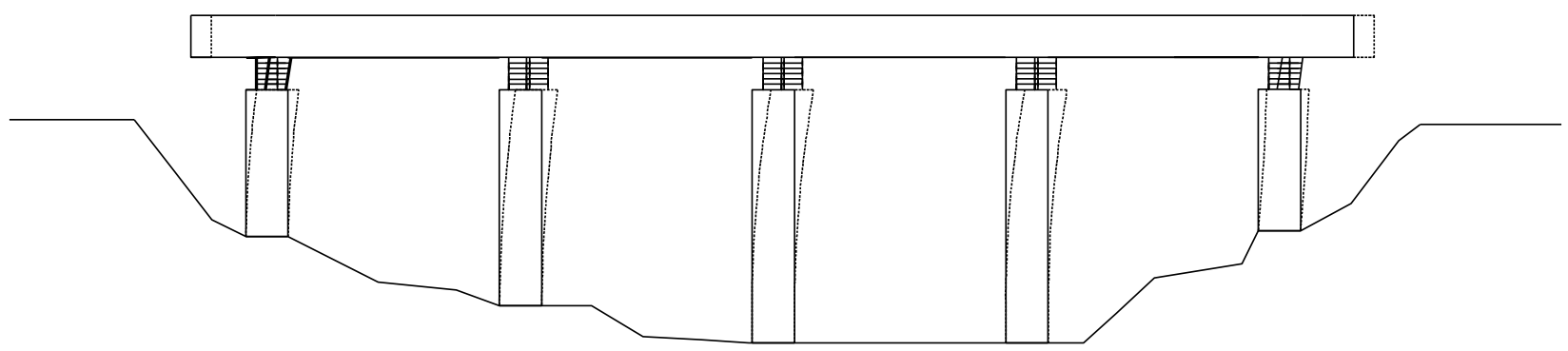

Figure 6. Qualitative visualization of the scheme where the deck imposes a common displacement at all piers and the shorter piers need the additional deformation of the bearings to accommodate the deck's displacement in comparison with the taller ones. 
Total Period

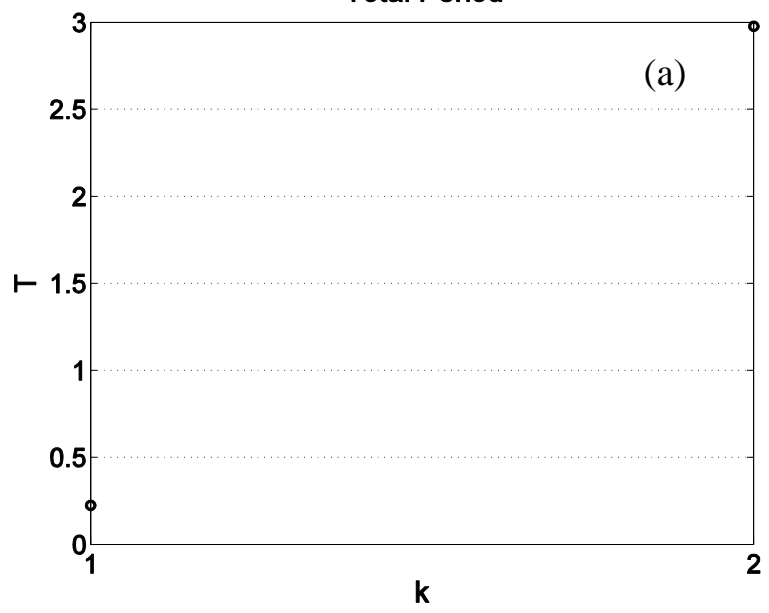

Total Period

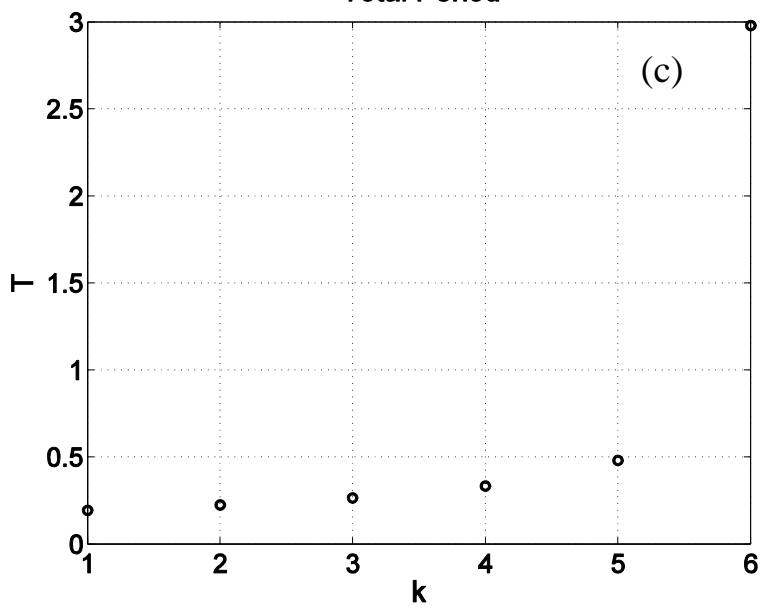

Total Period
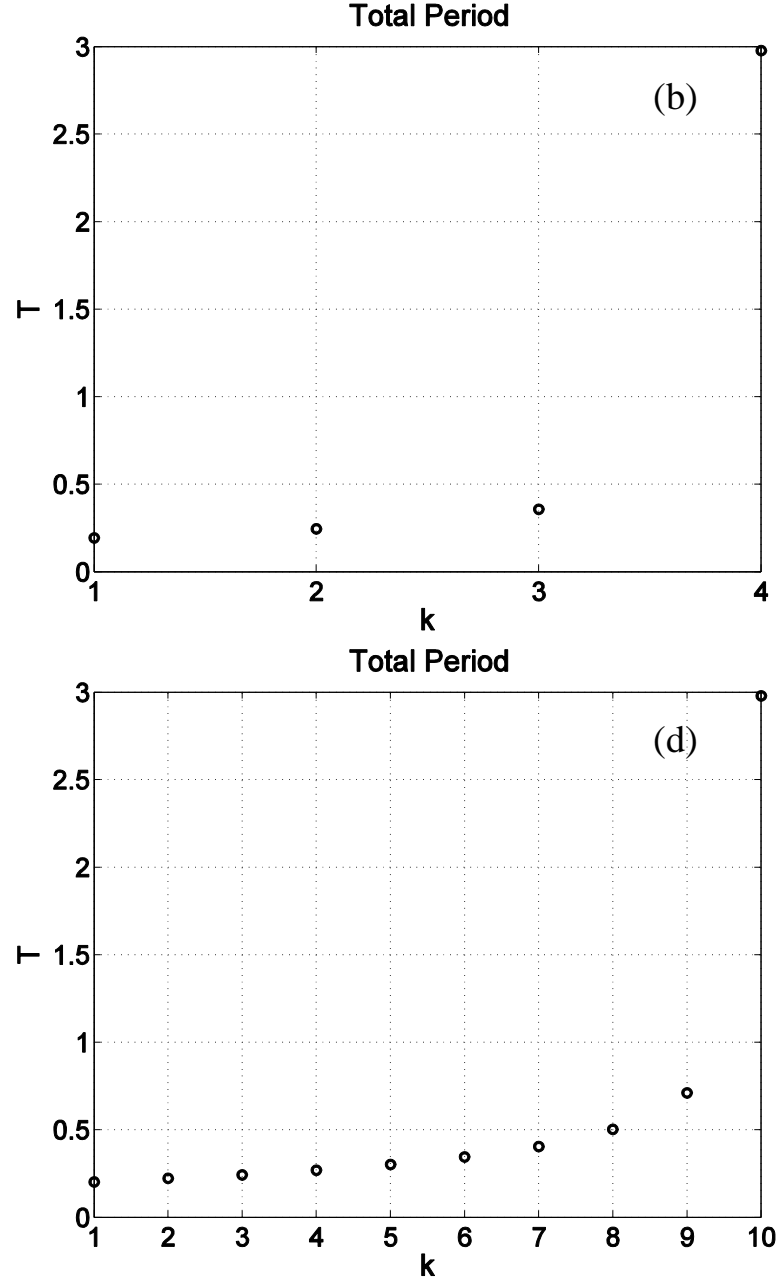

Figure 7. Modal periods of the states that emerge from the SDOF model of Fig.7 as a function of the engagement bearings, $k$, for $n=2$ (top left); $n=4$ (top right); $n=6$ (bottom left); $n=10$ (bottom right) under the assumption that the pier stiffness's are inversely proportional to their numbering according to Fig.7. 


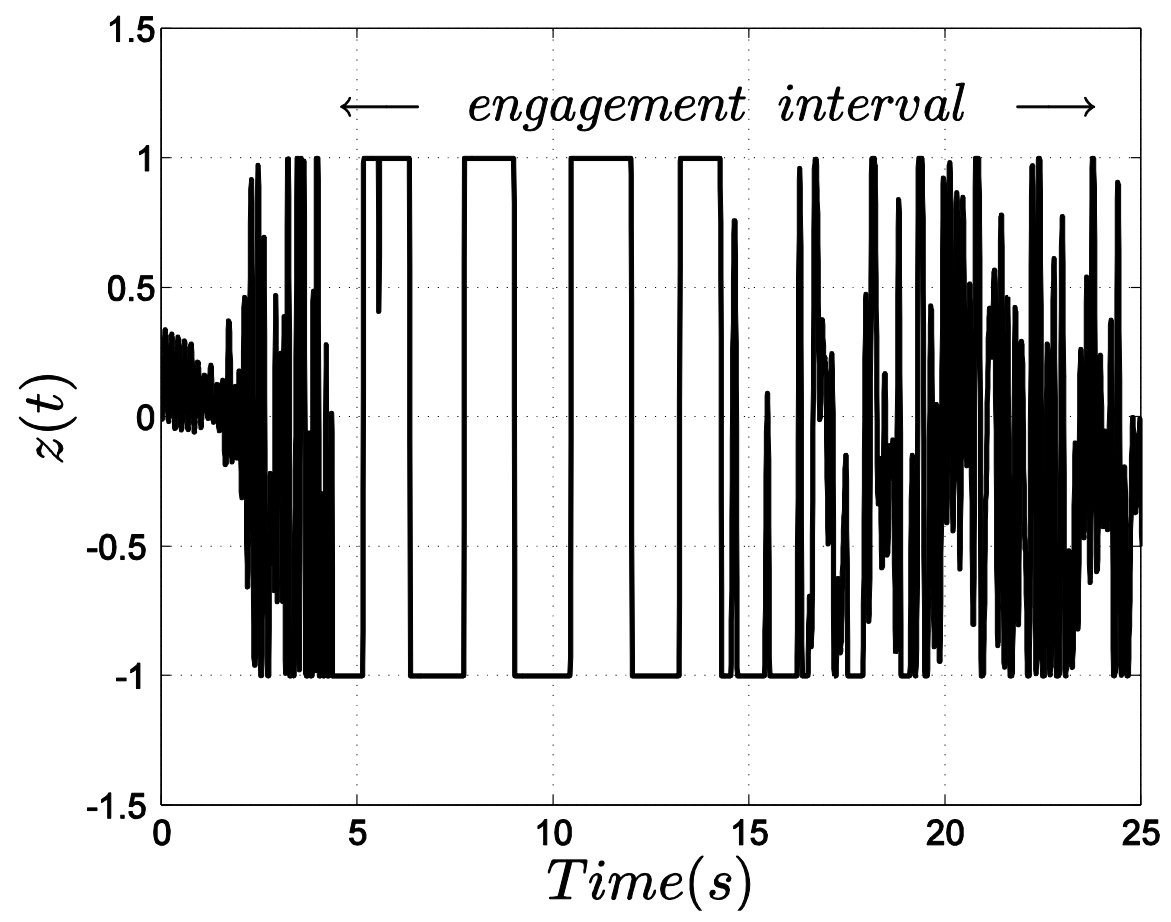

Figure 8. Definition of the engagement interval in the $z(t)$ signal from the first value of -1 or 1 to the last value of -1 or 1 .

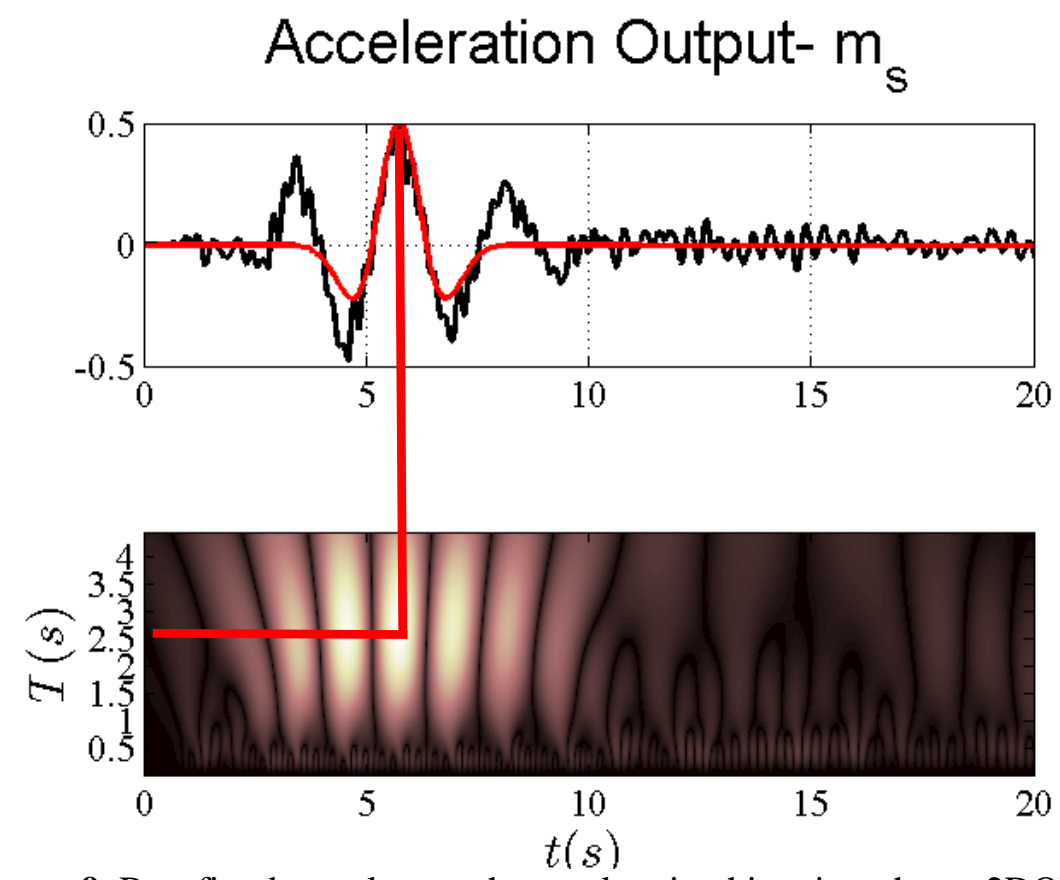

Figure 9. Best fitted wavelets on the acceleration histories when a 2DOF system is subjected to the 1992 Erzincan earthquake together with the associated scalograms. 
1979 Imperial Valley, E1 Centro Array\#5
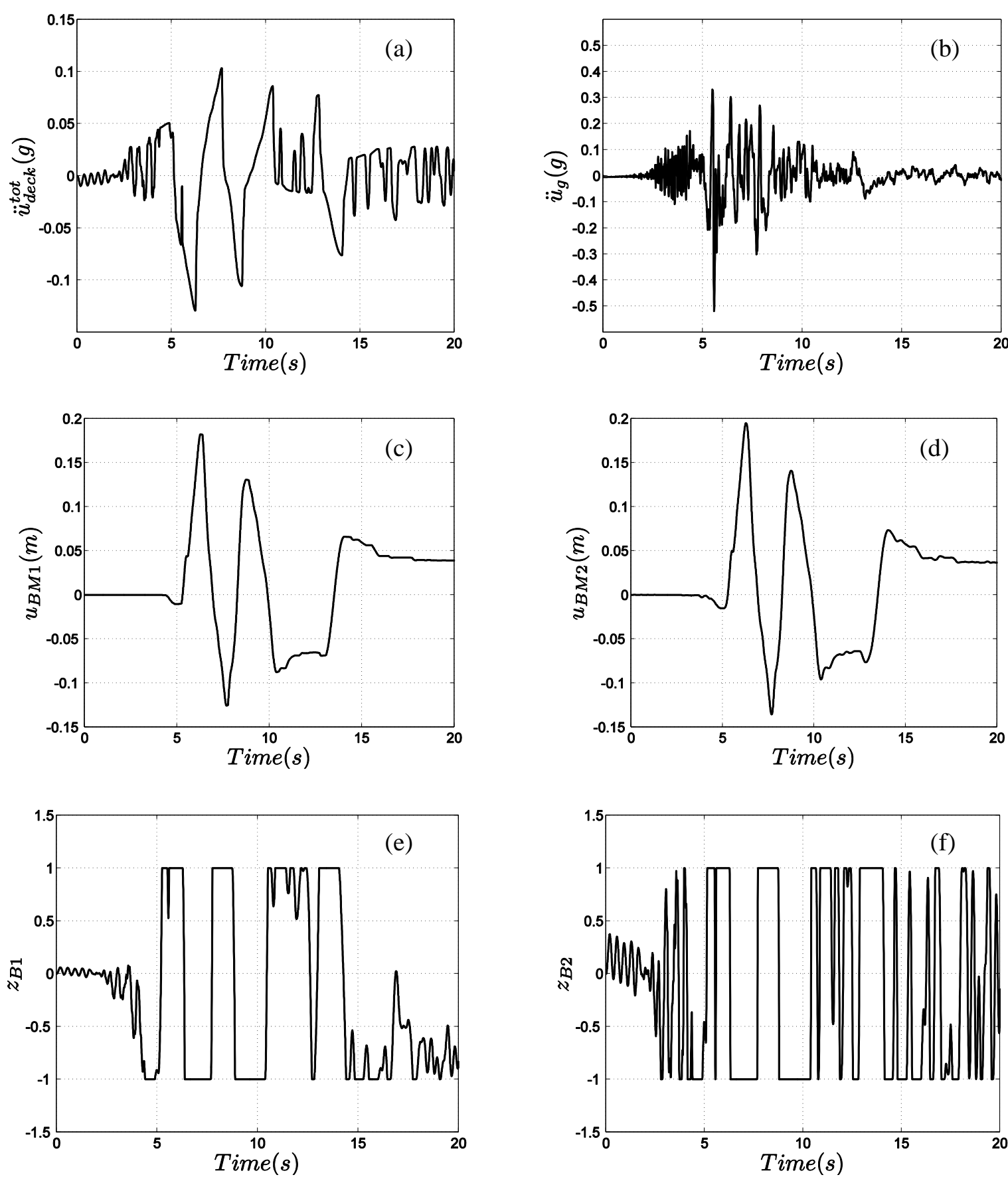

Figure 7. Deck acceleration (top-left); ground motion (top-right); displacement of the SSB at $M_{1}$ (middle-left); displacement of the SSB at $M_{2}$ (middle-right); $z_{B 1}(t)$ of the SSB at $M_{1}$ (bottom-left); $z_{B 2}(t)$ of the SSB at $M_{2}$ (bottom-right). 


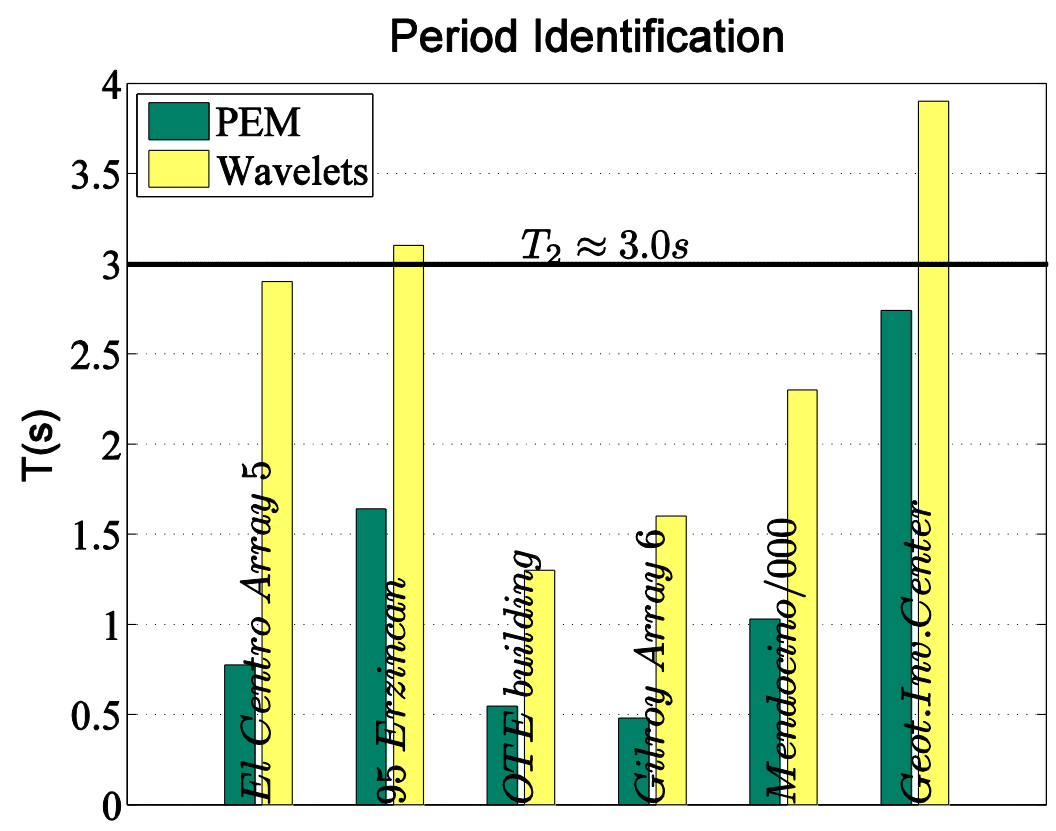

Figure 8. Modal periods identified from the application of PEM and Wavelet method on the total signal of the response acceleration of the deck. 


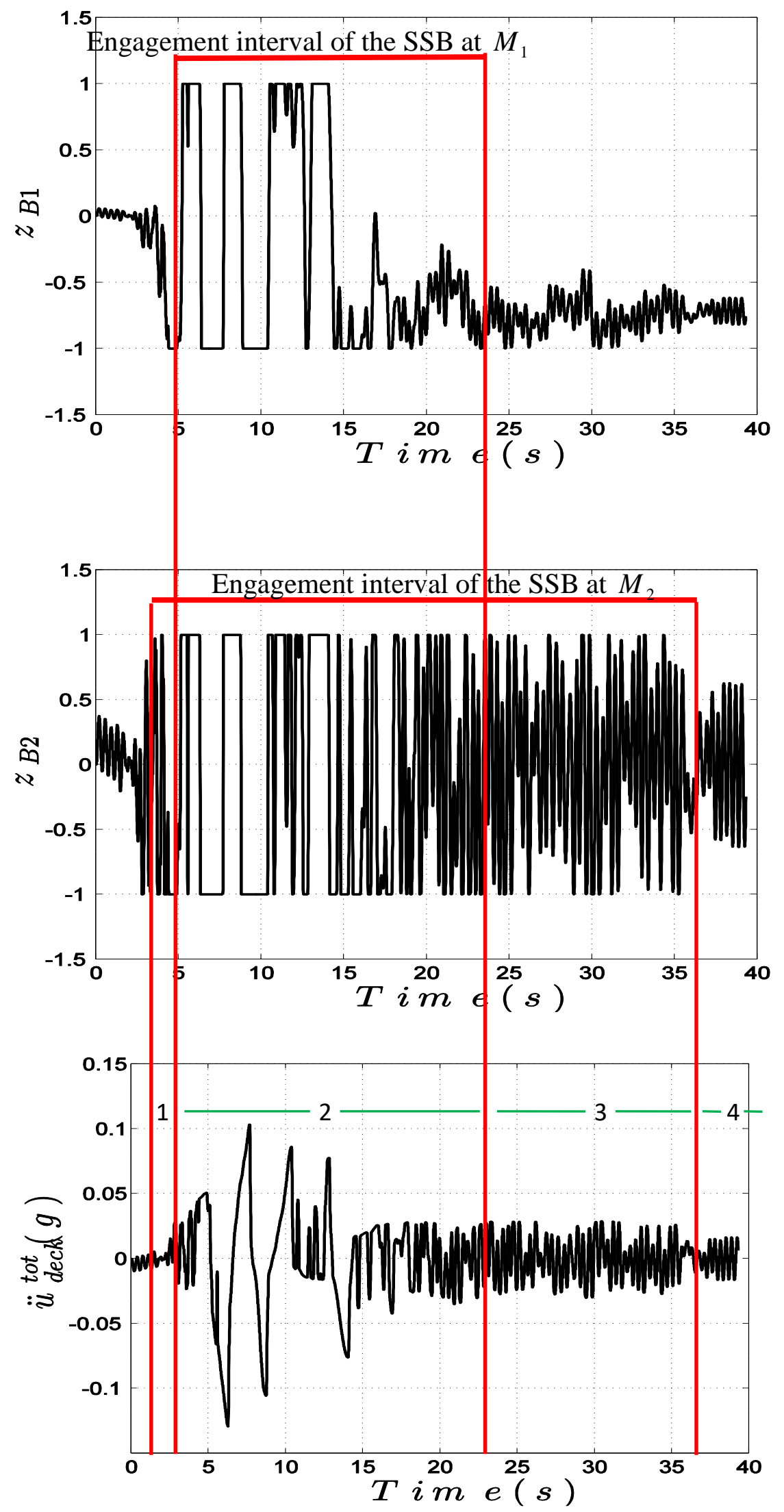

Figure 9. Separation of the time intervals on the total deck acceleration (bottom) by using the engagement intervals of the SSBs at $M_{1}$ (top) and $M_{2}$ (middle) when the bridge is subjected to El Centro Array \#5 record. 


\section{Imperial Valley, E1 Centro Array\#5}
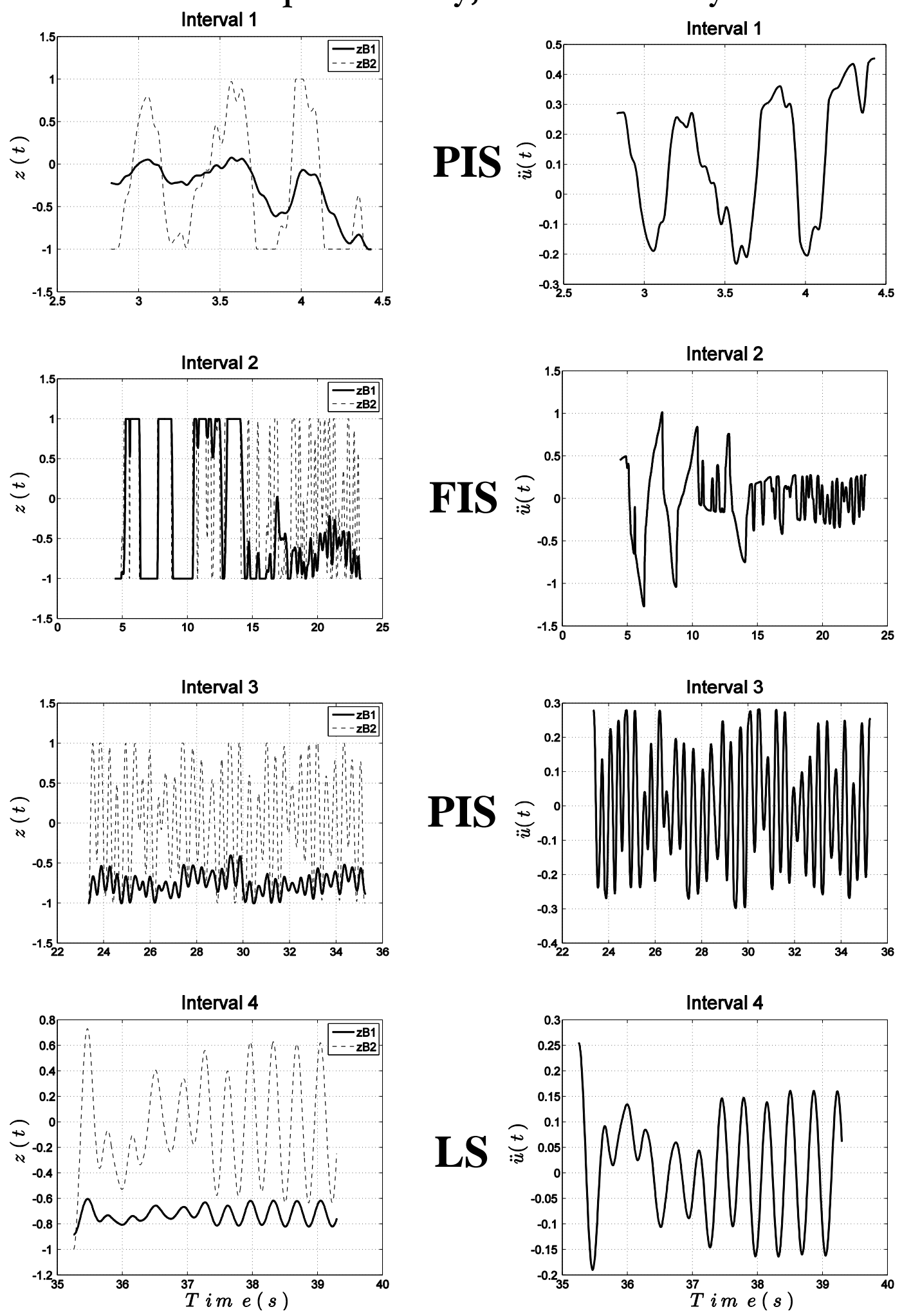

Figure 10. Responses of the emerging states (LS, PIS, FIS) as part of the total acceleration response of the deck. Left: the internal variables $z_{B 1}(t)$ and $z_{B 2}(t)$ of the SSBs at pier $M_{1}$ and $M_{2}$; Right: corresponding acceleration responses in the case of El Centro Array \#5 record. 


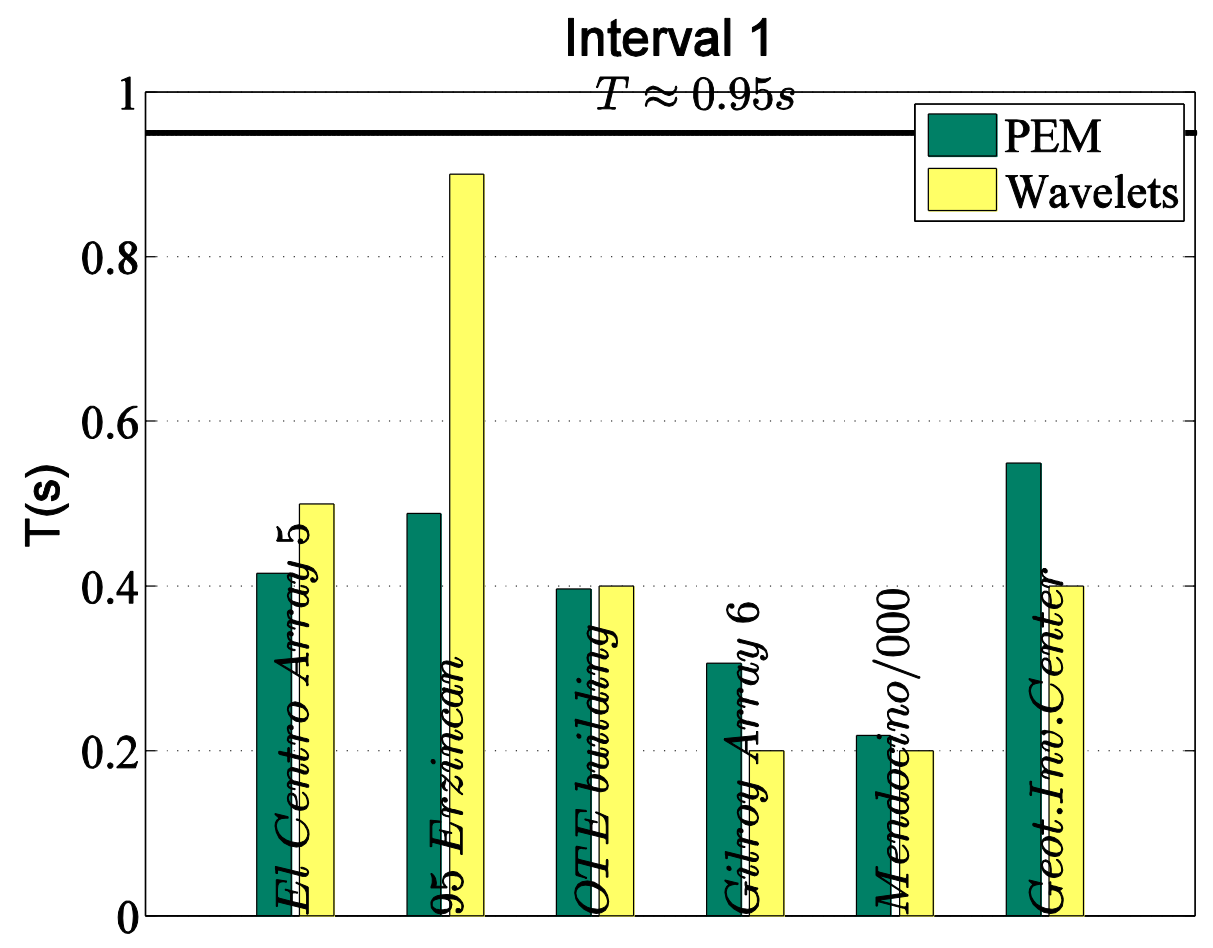

Figure 11. Modal periods identified with PEM and Wavelet method on interval 1 (PIS) of the response acceleration of the deck.

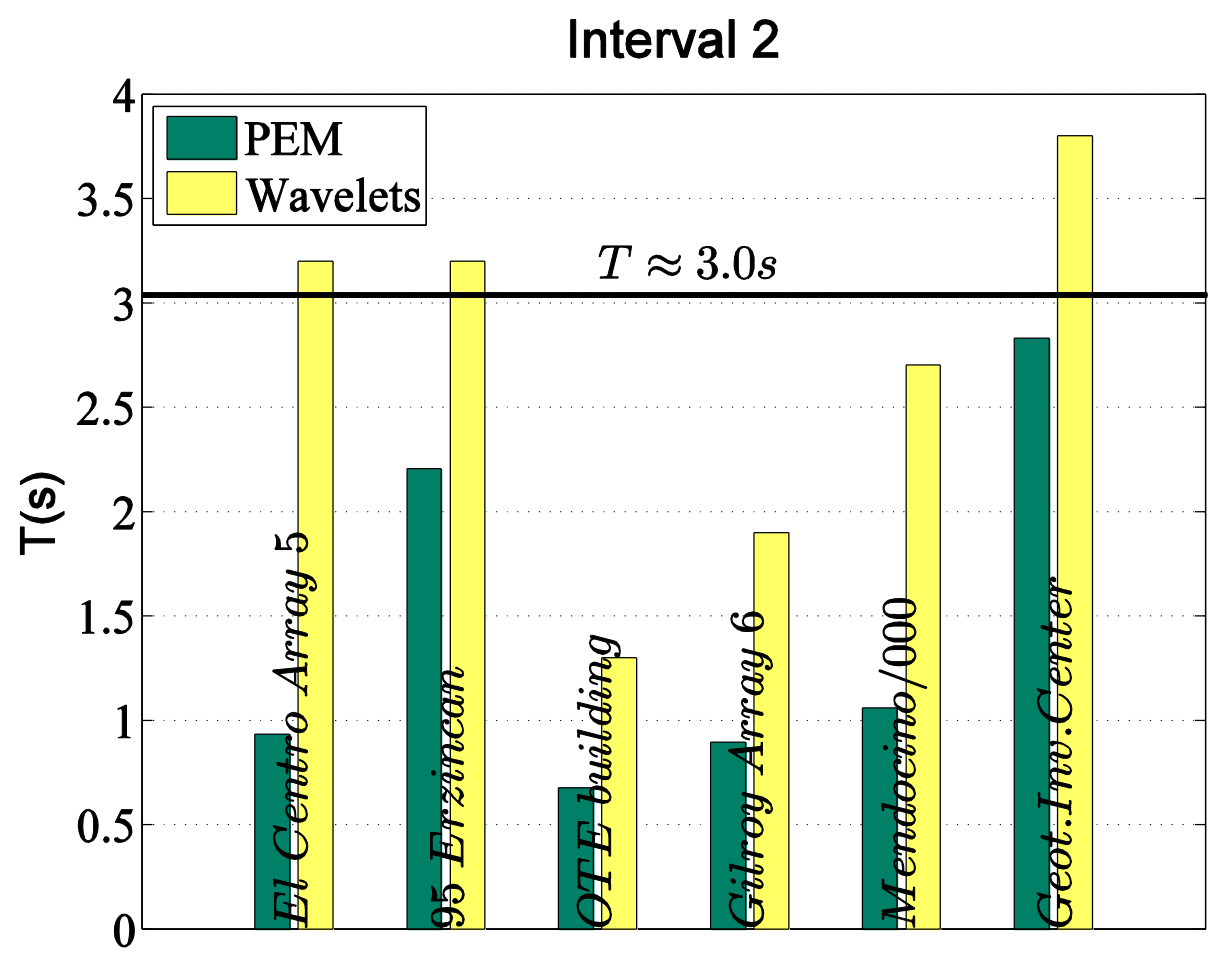

Figure 12. Modal periods identified with PEM and Wavelet method on interval 2 (FIS) of the response acceleration of the deck. 


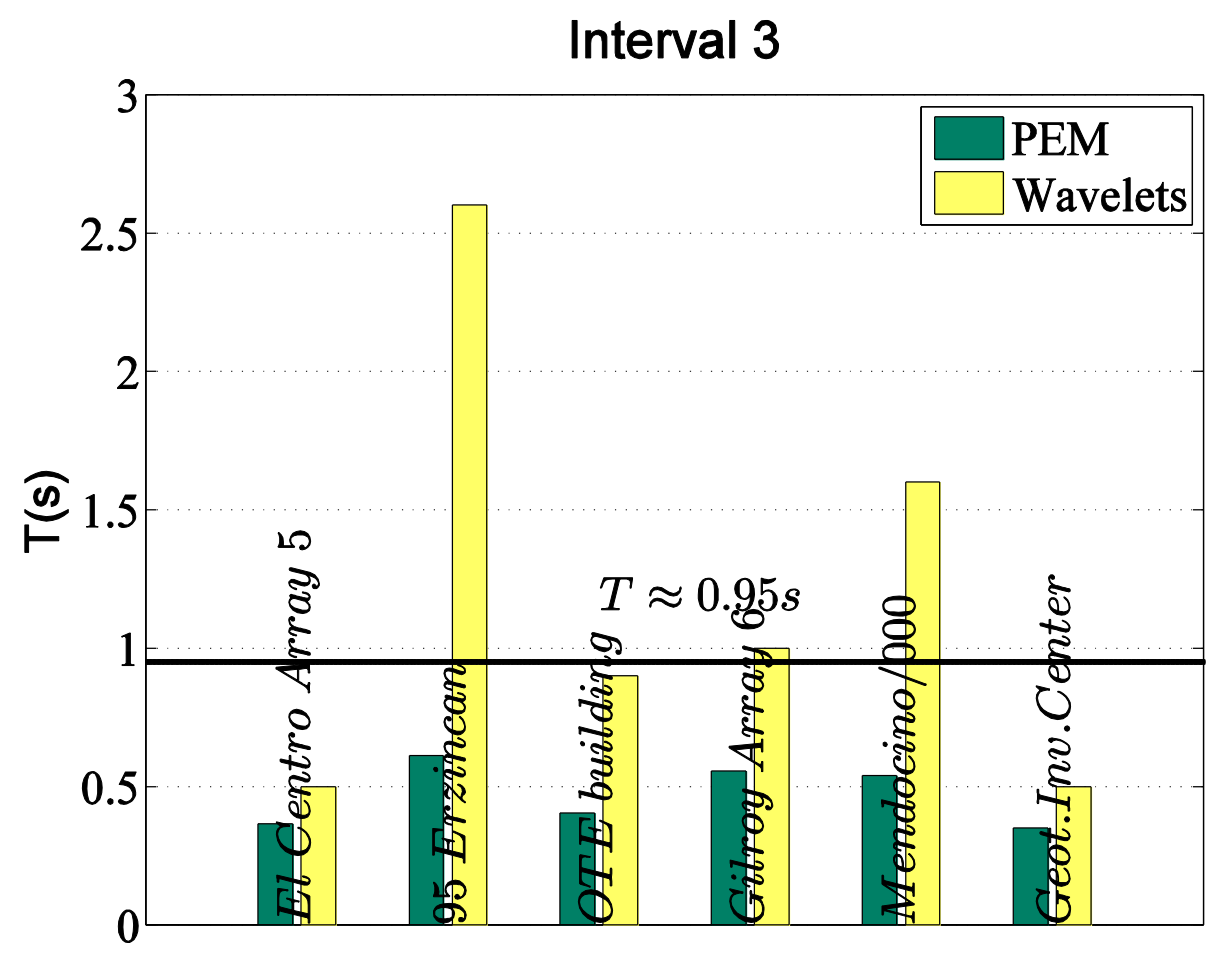

Figure 13. Modal periods identified with PEM and Wavelet method on interval 3 (PIS) of the response acceleration of the deck.

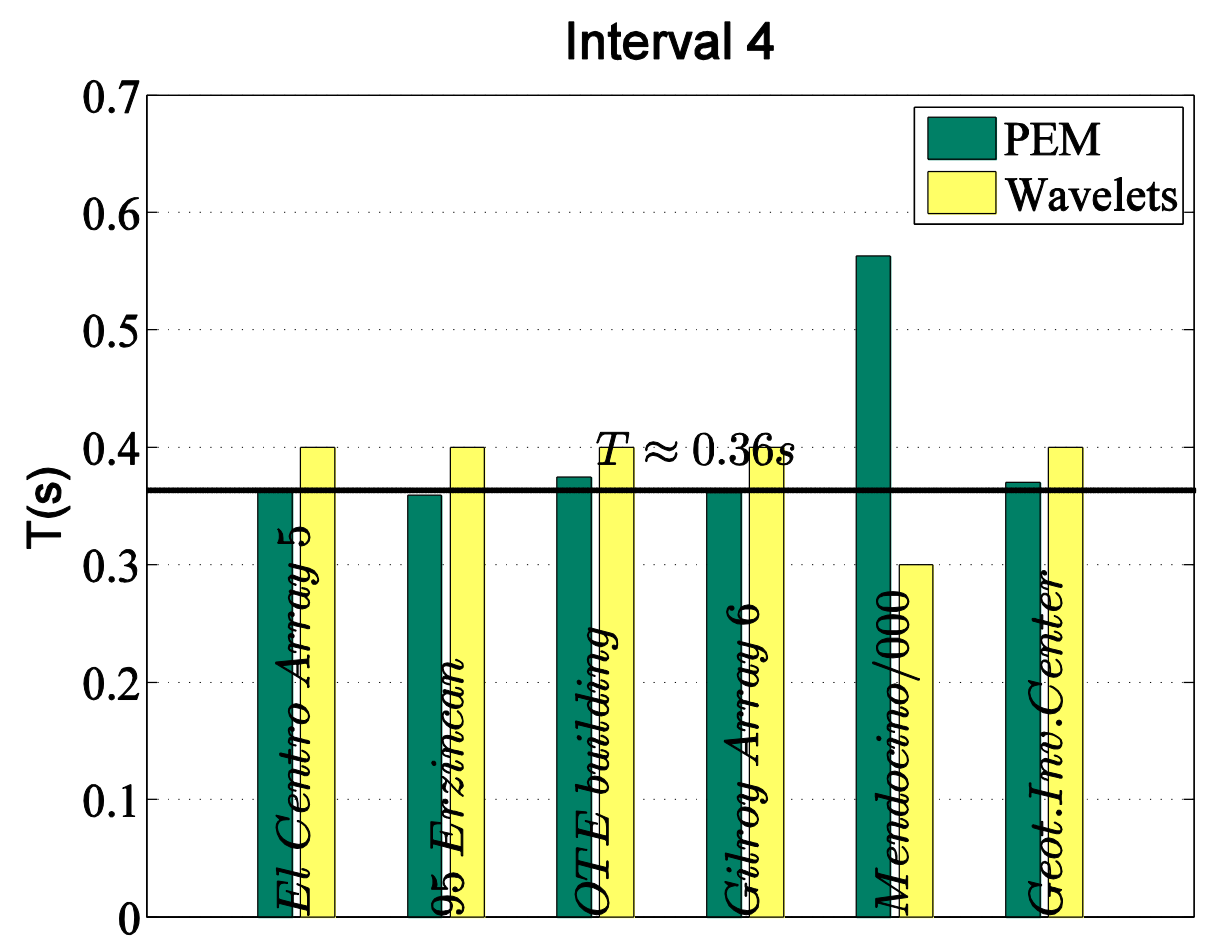

Figure 14. Modal periods identified with PEM and Wavelet method on interval 4 (LS) of the response acceleration of the deck. 


\section{Error PEM}

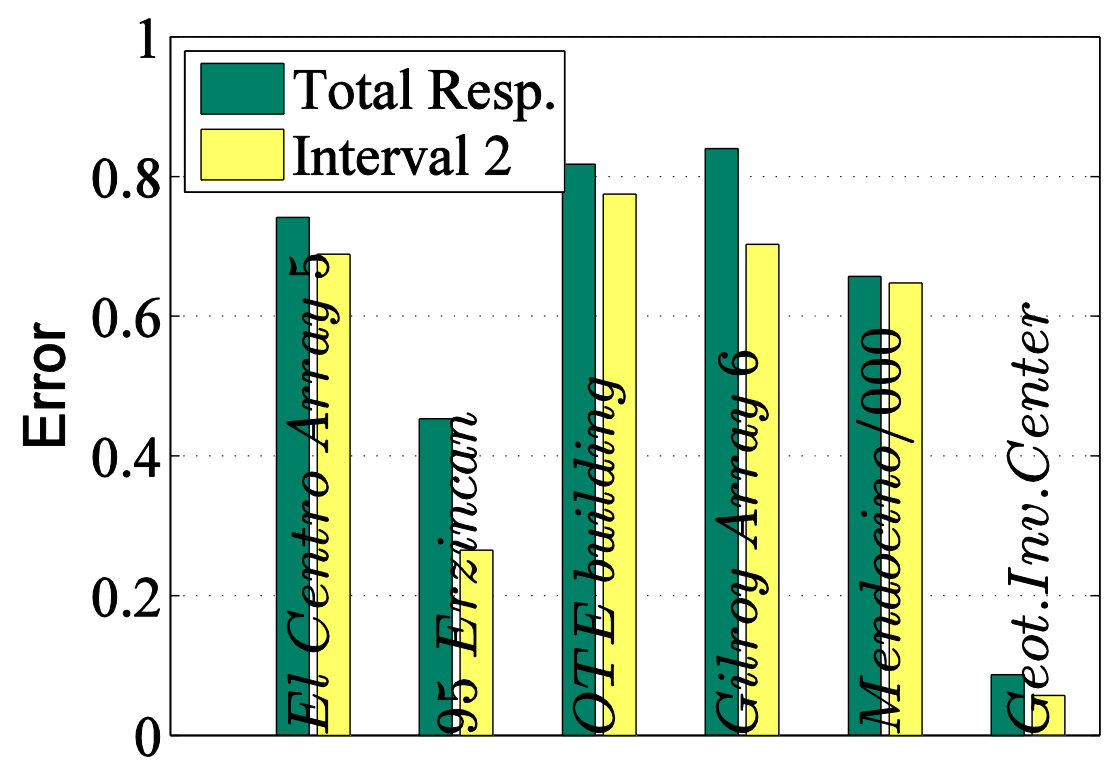

Figure 15. The error between the identified and the actual modal period of the bridge either by applying the PEM on the total response signal of the deck (green) or on time interval 2 (yellow).

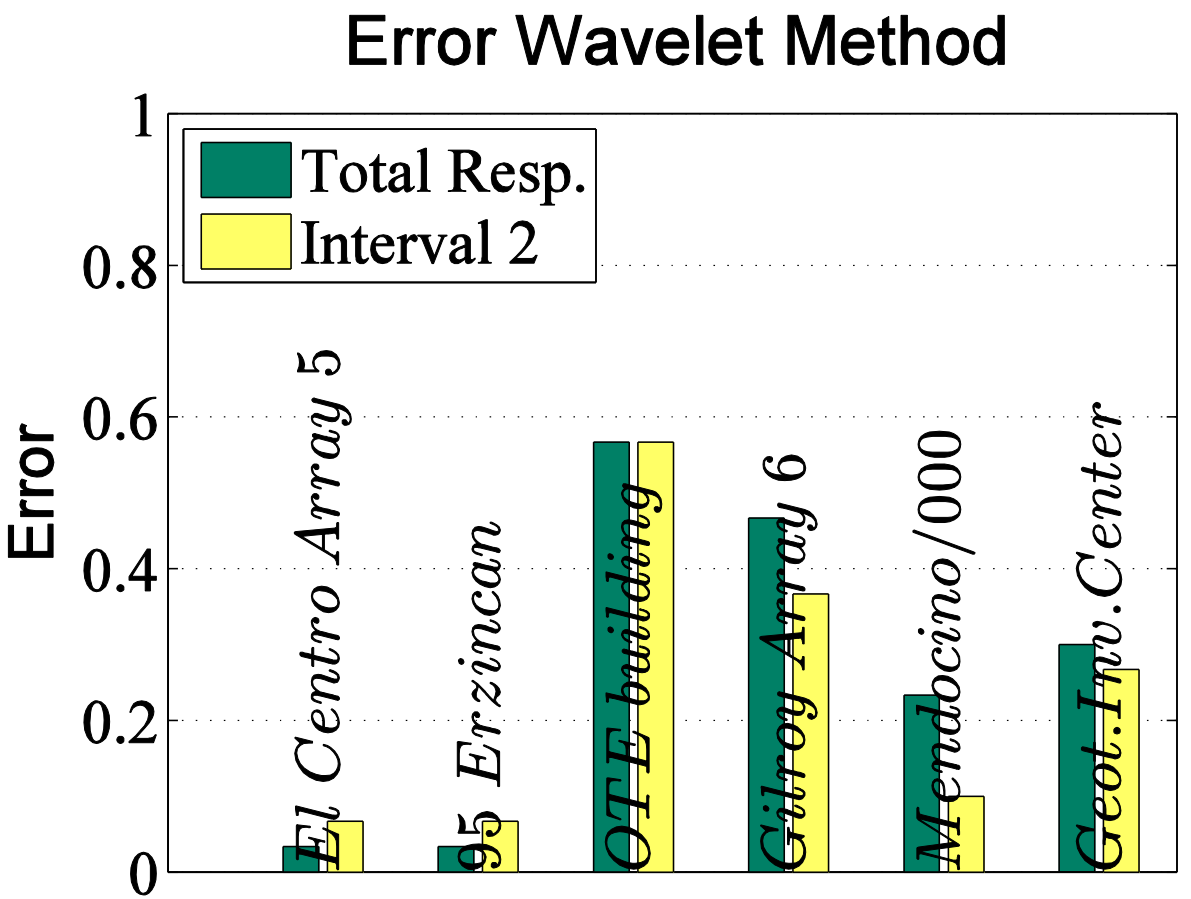

Figure 16. The error between the identified and the actual modal period of the bridge either by applying the Wavelet method on the total response signal of the deck (green) or on time interval 2 (yellow). 